\title{
Highly water soluble room temperature superionic liquids of APIs
}

Received 00th January 20xx, Accepted 00th January 20xx

DOI: $10.1039 / x 0 \times x 00000 x$
Gonçalo V. S. M. Carrera, ${ }^{a}+\dagger$, Miguel M. Santos, ${ }^{a},+$ Alexandra Costa, ${ }^{a}$ Luis Paulo N. Rebelo, ${ }^{a}$ Isabel M. Marrucho, ${ }^{b, c}$ M. Nunes da Ponte, ${ }^{a}$ Luis C. Branco ${ }^{a, *}$

www.rsc.org/

Herein a straightforward approach for the enhancement of water solubility of common antibiotic and NSAID Active Pharmaceutical Ingredients (APIs) is presented. The APIs are converted into lonic Liquids (API-ILs) and molten salts by combination with the organic superbases TMG, DBU and DBN. The prepared superionic liquids were characterized by ${ }^{1} \mathrm{H}$ and ${ }^{13} \mathrm{C}$ NMR as well as FTIR spectroscopy and elemental analysis. Most products are amorphous non-polymorphic Room Temperature Ionic Liquids with very high solubility in water, which may enhance the bioavailability of the API-ILs in comparison with the parent drugs.

The virtually infinite possibility of cation and anion combinations in Ionic Liquids (ILs) ${ }^{1}$ makes them a class of compounds with fine-tunable physicochemical properties as well as biological and pharmaceutical activities which allows their use over a broad range of fields. Protic ionic liquids (PILs) are obtained by an acid-base reaction between a proton donor and an acceptor that establish very stable hydrogen bond interactions. ${ }^{2}$ An appropriate choice of acids and bases can lead to the formation of task specific PILs, for instance in organic synthesis, fuel cells, explosives as well as analytical and biological applications. . $^{3,4}$ Such compounds are considered ionic if the acid and base (conjugated acid) species possess a pKa difference higher than $4 .{ }^{5}$ This is particularly attainable with organic superbases, which generally display pKa values higher than 10 , as they easily protonate other molecules and establish very stable anion-cation interactions. Infact, the socalled superionic liquids have been studied for biomass processing, $\mathrm{CO}_{2} / \mathrm{SO}_{2}$ capture and catalysis. ${ }^{4}$

Nowadays, the pharmaceutical industry faces a series of

a. LAQV-REQUIMTE, Departamento de Química, Faculdade de Ciências e Tecnologia, Universidade Nova de Lisboa, 2829-516 Caparica, Portugal.

b. Instituto de Tecnologia Química e Biológica, Universidade Nova de Lisboa,

Avenida da República, Estação Agronómica Nacional, 2780-157, Oeiras, Portugal.

c. Centro de Química Estrutural, Instituto Superior Técnico, Universidade de Lisboa,

Avenida Rovisco Pais, 1049-001 Lisboa, Portugal.

t These authors contributed equally.

Electronic Supplementary Information (ESI) available: experimental procedures, compound characterization data, NMR and FTIR spectra, and DSC thermograms. See DOI: 10.1039/x0xx00000x challenges related with the methodologies used in the discovery of new effective drugs. The convenient manipulation of solid APIs in order to ease the formulation of the drugs walks alongside with many disadvantages such as polymorphic conversion, low bioavailability associated with crystalline solids, and the tendency of amorphous forms to spontaneously crystallize. For these reasons, and due to legal conflicts related with different polymorphs, the use of an active drug in liquid form can be a reliable solution. ${ }^{6,7}$ The bioavailability of pharmaceutical drugs depends critically on their water solubility. Many phase II trials of new prospective Active Pharmaceutical Ingredients (APIs) fail because of their poor solubility in water and biological fluids. 6,8 The most common strategy used by the pharmaceutical industry in order to increase bioavailability is still to transform the API into a salt, usually by combining it with sodium or potassium. Recently, the use of APIs as Ionic Liquids (API-ILs) as an alternative has been investigated by the academy. ${ }^{7}$ The works involving the preparation of API-ILs from ampicillin, ${ }^{9,10}$ fluoroquinolones, ${ }^{11}$ ibuprofen, ${ }^{7}$ ranitidine ${ }^{7}$ and lidocaine, ${ }^{7}$ and also acetylsalicylic and salicylic acids, ${ }^{12}$ among others, ${ }^{13}$ have shown that the combination of an API, either as a cation or as an anion, with a suitable biocompatible counter-ion can increase the water solubility of the parent drug and even change its biological effect. ${ }^{14,15}$ In face of these results it is suggested that the oral bioavailability of the formed API-ILs is particularly enhanced, or alternatively it may open new perspectives for their local administration/application. Therefore, the therapeutic dosage of the drug may be reduced, thereby decreasing side effects. Herein, a new efficient methodology for the preparation of API-ILs is presented and discussed. It transforms poorly water soluble, neutral APIs bearing one carboxylic acid appendage into highly water soluble ILs or molten salts by combination with organic superbases (Figure 1).

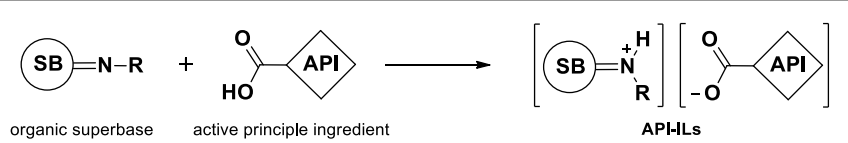

Figure 1. Preparation of protic API-ILs by direct protonation of superbases. 
The three superbases 1,1,3,3-tetramethylguanidine (TMG), 1,8-diazabicyclo[5.4.0] undec-7-ene (DBU) and 1,5diazabicyclo(4.3.0)non-5-ene (DBN) were coupled with several antibiotic and NSAID APIs. In the antibiotic family, ampicillin (AMP), ciprofloxacin (CIP) and norfloxacin (NOR) were used, as well as 6-aminopenicellanic acid (APA), which is a synthetic intermediate in the synthesis of penicillin derivatives. The chosen NSAIDs were ibuprofen (IBU) and naproxen (NPX). The structure of the 17 new ionic liquids and molten salts is displayed in Figure 2.

Bearing in mind the potential pharmaceutical application of these ionic liquids, we would like to stress that in general protic ILs are usually less toxic than the aprotic ones. ${ }^{16-21}$

All prepared salts were obtained in high yield (89 to 100\%) and purity levels using a sustainable synthetic methodology which guarantees an atom economy process. All novel API ionic liquids or salts were completely characterized by spectroscopic techniques, namely ${ }^{1} \mathrm{H}$ and ${ }^{13} \mathrm{C}$ NMR and FTIR, and elemental analysis. Additionally, the thermal properties of the final products were evaluated by calorimetric studies (DSC analysis) and their solubility in water was also determined.

Table 1 summarizes relevant ${ }^{13} \mathrm{C}$ NMR and FTIR spectroscopic data of the novel TMG-, DBU- and DBN-based salts and parent APIs. It is possible to conclude by ${ }^{1} \mathrm{H}$ and ${ }^{13} \mathrm{C}$ NMR data that all reactions reached completion (only one set of signals was observed in every spectrum). In the case of [TMGH]-based compounds, the protonation of TMG induces a significant shielding increase of the guanidinium quaternary carbon atom which is expressed by a characteristic upfield deviation of the ${ }^{13} \mathrm{C}$ NMR resonance of this atom. ${ }^{22}$ More precisely, the given signal varies ca. $5 \mathrm{ppm}$ from $\delta 167.8 \mathrm{ppm}$ for the neutral TMG in $\mathrm{CDCl}_{3}$ up to $\delta$ values between $162.8-162.1 \mathrm{ppm}$ for the TMG based salts of [NPX], [IBU], [APA] and [AMP] (Table 1). For [CIP]- and [NOR]-based salts, the corresponding upfield variation was 5.9 and $2.3 \mathrm{ppm}$ in $\mathrm{CD}_{3} \mathrm{OD}$ and $\mathrm{DMSO}-\mathrm{d}^{6}$, respectively. On the other hand, for the [DBUH]- and [DBNH] based salts the variation of the ${ }^{13} \mathrm{C} N M R$ resonance of the quaternary carbon $\mathrm{C}=\mathrm{N}^{+}$occurs downfield as reported, ${ }^{23}$ reflecting the weaker shielding of the protonated amidine core. When the spectra are collected in $\mathrm{CDCl}_{3}$, the observed variation is ca. $4.5 \mathrm{ppm}$ for both groups of PILs, but increases to almost $8 \mathrm{ppm}$ in DMSO- $d^{6}$ and reduces to $c a .3 \mathrm{ppm}$ in $\mathrm{CD}_{3} \mathrm{OD}$.

(1)

Figure 2. Molecular structure of the APIs and superbases (SB) used.
Table $1 .{ }^{13} \mathrm{C}$ NMR and FTIR data of the prepared salts, superbases (SB) and APIs

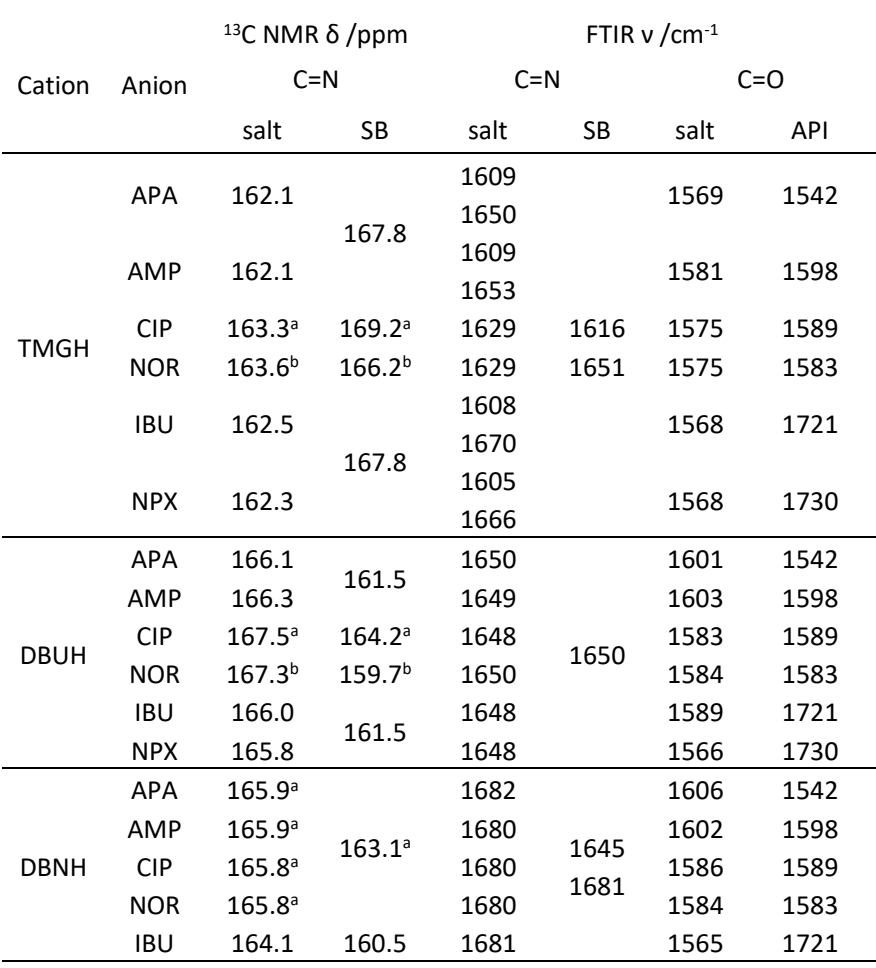

$\mathrm{CDCl}_{3}$ was the solvent for all ${ }^{13} \mathrm{C}$ NMR spectra except a) $\mathrm{CD}_{3} \mathrm{OD}$ and b) DMSO- $d^{6}$.

Additionally, the ${ }^{13} \mathrm{C}$ NMR resonance of the quaternary carbon atom of the anion's carboxylate group is, as expected, deviated from the corresponding group in the parent APIs. This variation is more discrete, ca. $1 \mathrm{ppm}$, than the ones reported for the quaternary carbon atom of the guanidinium and amidinium cations, and is in agreement with the stabilized resonance structure of the carboxylate groups. This comparison can only be performed for the [NPX]-, [IBU]- and [AMP]-based salts as the remaining parent APIs were not soluble in the same deuterated solvents.

The formation of the desired salts is also supported by FTIR data (Table 1). On one hand, all spectra showed a medium to high intensity band between 1606 and $1565 \mathrm{~cm}^{-1}$ which is consistent with the characteristic vibration of the $\mathrm{CO}_{2}^{-}$group of the anionic APIs. This is particularly manifest for the salts containing [IBU] and [NPX] because the carboxylic acid group of the parent APIs is completely protonated before combination with the superbases, according to their nonzwitterionic nature. On the other hand, the formation of the salts can also be evaluated by changes in the vibration modes of the superbases' C-N bonds. In the neat state, both TMG and DBN exhibit two vibrational modes between $1700-1600 \mathrm{~cm}^{-1}$ of similar intensity, more precisely $1651\left(v_{\mathrm{T} 1}\right)$ and $1616\left(\mathrm{~V}_{\mathrm{T} 2}\right) \mathrm{cm}^{-1}$ for the former and $1681\left(v_{D 1}\right)$ and $1645\left(v_{D 2}\right) \mathrm{cm}^{-1}$ for the latter. Upon combination with [APA], [AMP], [IBU] and [NPX], the FTIR spectra of [TMGH]-based salts show that $\mathrm{v}_{\mathrm{T} 2}$ becomes the most intense band, with a slight deviation to lower wavenumbers (1609-1605 $\mathrm{cm}^{-1}$ ), while $v_{\mathrm{T} 1}$ remains practically unchanged. In the case of the [TMGH][CIP] and [TMGH][NOR] salts, $\mathrm{V}_{\mathrm{T} 1}$ and $\mathrm{V}_{\mathrm{T} 2}$ appear superimposed with the very strong 
band corresponding to $\mathrm{N}-\mathrm{H}$ stretching from the amines of the anion at $1629 \mathrm{~cm}^{-1}$. In contrast, the FTIR spectrum of the [DBNH]-based salts show the vibrational mode $v_{D 1}$ with minor variations in wavelength. Finally, the $\mathrm{N}-\mathrm{H}$ stretching vibration of DBU at $1650 \mathrm{~cm}^{-1}$ remains practically unaltered upon combination with the corresponding APIs.

Considering the data presented in Table 1 , it is possible to observe that the variation between the wavenumber values for the asymmetrical stretch of the carboxylate and carboxylic acid groups of the starting APIs and the final compounds is higher for the [TMGH]-based salts than for the ones with the other organic superbases. This observation is in complete agreement with a more stable interaction between the APIs and TMG than with the other superbases, given its highest $\mathrm{pKa}$ value (13.6) in comparison with DBU (11.5) and DBN (12.7). Taking into account the structures of the carboxylate and the guanidine groups, we suggest that the cation-anion interaction takes place through a hexagonal structure stabilized by hydrogen bonds as depicted in Figure 3 .

Table 2 contains the collected data from the calorimetric (DSC) studies. All salts containing [APA] and [AMP], as well as [DBNH][NOR], [DBUH][IBU], [DBNH][IBU] and [DBUH][NPX] are orange, yellow or colorless pastes, thus are considered Room Temperature lonic Liquids. The melting temperature of these RTILs was not observed through Differential Scanning Calorimetry (DSC) studies conducted between $-90{ }^{\circ} \mathrm{C}$ and $150{ }^{\circ} \mathrm{C}$, although some presented glass transition temperatures $\left(\mathrm{T}_{\mathrm{g}}\right)$ consistent with amorphous structures. Figure 4 contains the DSC data of three of the prepared RTILs, more specifically $[D B N H][N O R],[D B U H][I B U]$ and [DBUH][NPX], which are extremely soluble in water (vide infra). The remaining salts are solids that melt at temperatures higher than $148{ }^{\circ} \mathrm{C}$ except for [TMGH][IBU]. The observed physical state of these compounds is in agreement with the strength of the anion-cation interactions described above. In other words, once TMG tends to yield more stable associations with the APIs, there is a higher tendency of these ionic compounds to possess higher melting points than the ones with the remaining superbases, which establish weaker interactions given the $\Delta \mathrm{pKa}$ between the SBs and APIs. Finally, none of the prepared RTILs and salts present polymorphic structures, contrarily to the parent APIs. ${ }^{26-30}$

It is worth mentioning that the prepared RTILs show a very significant increase of solubility in water in comparison with the parent APIs as opposed to the solid salts (see Figure 5). In addition, [DBNH] seems to be the best cation in terms of water solubility with three out of five APIs. In fact, the most striking results were recorded for [DBNH][NOR] and [DBNH][IBU], as well as [DBUH][NPX], which were soluble in only $5 \mu \mathrm{L}$ of water $\left(c>7 \mathrm{~g} \cdot \mathrm{mL}^{-1}\right)$.

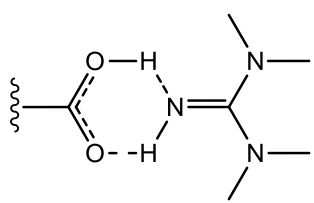

Figure 3. Six-membered ring structure stabilized by hydrogen bonds between a generic carboxylic acid moiety from an API and the guanidine from TMG.
Table 2. Physical state, melting and glass transition temperatures of the salts and APIs.

\begin{tabular}{|c|c|c|c|c|c|}
\hline \multirow{2}{*}{ Cation } & \multirow{2}{*}{ Anion } & \multirow{2}{*}{ Physical state } & \multicolumn{2}{|c|}{$\mathrm{Tm}^{a} /{ }^{\circ} \mathrm{C}$} & \multirow{2}{*}{$\mathrm{Tg}_{\mathrm{g}}^{\mathrm{b}} /{ }^{\circ} \mathrm{C}$} \\
\hline & & & salt & $A P I^{c}$ & \\
\hline \multirow{3}{*}{ APA } & TMGH & Orange paste & liq. & \multirow{3}{*}{199} & 6.6 \\
\hline & DBUH & Orange paste & liq. & & 83.8 \\
\hline & DBNH & Orange paste & liq. & & 78.7 \\
\hline \multirow{3}{*}{ AMP } & TMGH & White paste & liq. & \multirow{3}{*}{208} & 114.6 \\
\hline & DBUH & White paste & liq. & & 105.1 \\
\hline & DBNH & Yellow paste & liq. & & 115.3 \\
\hline \multirow{3}{*}{ CIP } & TMGH & White solid & $>200$ & \multirow{3}{*}{256} & - \\
\hline & DBUH & White solid & $>200$ & & - \\
\hline & DBNH & White solid & $160 \mathrm{dec}$. & & 66.4 \\
\hline \multirow{3}{*}{ NOR } & TMGH & White solid & $>200$ & \multirow{3}{*}{227} & - \\
\hline & DBUH & Yellow solid & 160 & & - \\
\hline & DBNH & Yellow paste & liq. & & -0.4 \\
\hline \multirow{3}{*}{ IBU } & TMGH & White solid & $115.4^{*}$ & \multirow{3}{*}{76} & -11.8 \\
\hline & DBUH & Colorless paste & liq. & & -12.0 \\
\hline & DBNH & Colorless liquid & liq. & & -21.4 \\
\hline \multirow{2}{*}{ NPX } & TMGH & Yellow solid & 149 & \multirow{2}{*}{153} & - \\
\hline & DBUH & Yellow paste & liq. & & 20.1 \\
\hline
\end{tabular}

a Melting temperature $\left(T_{m}\right)$ of the salts was determined using a melting point apparatus *except for [TMGH][IBU], which was determined by DSC measurements. ${ }^{b}$ Glass transition temperature $\left(T_{g}\right)$ was determined by DSC measurements at a heating/cooling rate of $10{ }^{\circ} \mathrm{C} \mathrm{min}{ }^{-1} .{ }^{c} \mathrm{Tm}_{\mathrm{m}}$ of APIs from references $\mathrm{APA}^{24}, \mathrm{AMP}^{25}, \mathrm{CIP}^{24}, \mathrm{NOR}^{25}, \mathrm{IBU}^{25}, \mathrm{NPX}^{25}$.

From these three RTILs, the first and last ones are particularly relevant because the remaining [NOR] and [NPX] based salts were found to be insoluble in the tested concentrations $(c<6$ $\mathrm{mg} \cdot \mathrm{mL}^{-1}$ ). On the other hand, the $[\mathrm{TMGH}]$ and [DBUH] salts of [IBU] recorded, respectively, 35500- and 63500-fold increase in water solubility in comparison with the parent drug. [DBNH][APA] was also the most water soluble salt of the [APA] family, with over 1000 -fold increase comparing to the parent API. Similarly to NPX, it was the salt of [AMP] with [DBUH] that showed the highest value of water solubility. Finally, none of the [CIP] salts showed relevant water solubility.

Thus, through combination with the organic superbases TMG, DBU and DBN, we could, in a sustainable fashion, transform polymorphic APIs - AMP, NOR, IBU and NPX - or synthetic precursors (e.g. APA), into non-polymorphic amorphous Room

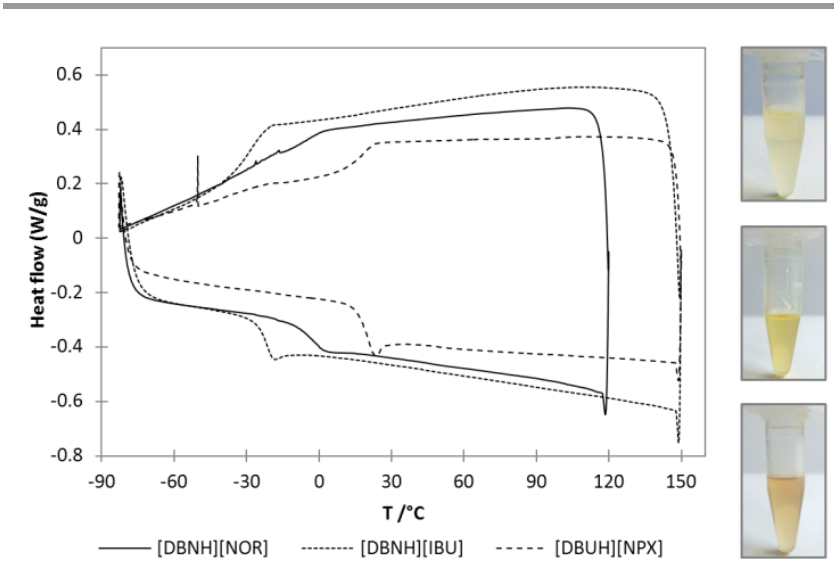

Figure 4. Pictures of $[\mathrm{DBNH}][\mathrm{NOR}],[\mathrm{DBUH}][\mathrm{IBU}]$ and $[\mathrm{DBUH}][\mathrm{NPX}]$ (from top to bottom), and corresponding DSC data. 


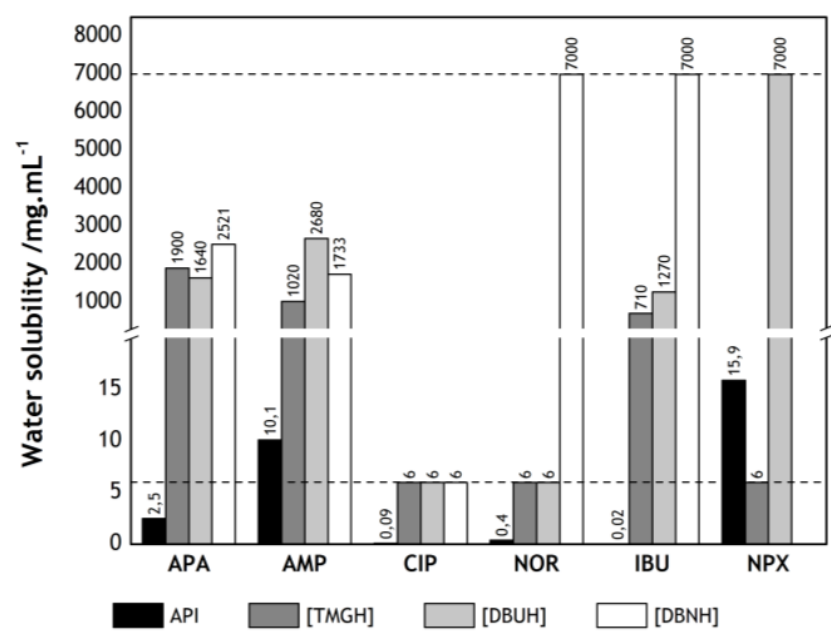

Figure 5. Plot of water solubility of the APIs and synthesized ILs. Water solubility of APIs from references APA, ${ }^{31} \mathrm{AMP},{ }^{32} \mathrm{CIP},{ }^{33} \mathrm{NOR},{ }^{33} \mathrm{IBU},{ }^{25} \mathrm{NPX} .{ }^{25}$ The high and low thresholds are respectively the highest and lowest concentrations in water of the API-ILs.

Temperature lonic Liquids or salts which, in the vast majority of cases, display extremely high solubility in water. These properties significantly affect the bioavailability of the APIs, as well as possibly their pharmaceutical effect. Future biological, toxicological and pharmaceutical studies will be performed soon with selected protic ILs and reported elsewhere.

\section{Acknowledgments}

This work was supported by Fundação para a Ciência e a Tecnologia through projects (PEst-C/LA0006/2013, PTDC/CTM/103664/2008, two contracts under Investigador FCT (L. C. Branco and I. M. Marrucho) and a Postdoctoral fellowship G. V. S. M. Carrera (SFRH/BPD/72095/ 2010) and Solchemar company. Authors also thank to Prof. Madalena Dionísio and Dr. Natália Correia for support with the DSC analyses.

\section{Notes and references}

1 A. R. Katritzky, R. Jain, A. Lomaka, R. Petrukhin, M. Karelson, A. E. Visser, R. D. Rogers, J. Chem. Inf. Comput. Sci., 2002, 42, 225-231.

2 M. S. Miran, H. Kinoshita, T. Yasuda, A. B. H. Susan, M. Watanabe, Chem. Commun., 2011, 47, 12676-12678.

3 T. L. Greaves, C. J. Drummond, Chem. Rev., 2008, 108, 206-237.

4 J. Nowicki, M. Muszyński, J.-P. Mikkola, RSC Adv., 2016, 6, 9194-9208.

5 J. Stoimenovski, E. I. Izgorodina, D. R. MacFarlane, Phys. Chem. Chem. Phys., 2010, 12, 10341-10347.

6 R. Ferraz, L. C. Branco, C. Prudêncio, J. P. Noronha, Z. Petrovski, ChemMedChem, 2011, 6, 975-985.

7 W. L. Hough, M Smiglak, H. Rodriguez, R. P. Swatloski, S. K. Spear, D. T. Daly, D. T., Pernak, J., Grisel, J. E., Carliss, R. D., Soutullo, M. D., Davis Jr., J. H., R. D. Rogers, New J. Chem., 2007, 31, 1429-1436.

8 D. Schuster, C. Laggner, T. Langer, Curr. Pharm. Des., 2005, 11, 3545-3549.

9 R. Ferraz, L. C. Branco, I. M. Marrucho, J. M. M. Araújo, L. P. N. Rebelo, M. Nunes da Ponte, C. Prudêncio, J. P.
Noronha, Z. Petrovski Med. Chem. Commun., 2012, 3, 494-497.

10 C. Florindo, J. M. M. Araújo, F. Alves, C. Matos, R. Ferraz, C. Prudêncio, J. P. Noronha, Z. Petrovski, L. Branco, L. P. N. Rebelo, I. M. Marrucho, Int. J. Pharm., 2013, 456, 553-559.

11 C. Florindo, A. Costa, C. Matos, S. L. Nunes, A. N. Matias, C. M. M. Duarte, L. P. N. Rebelo, L. C. Branco, I. M. Marrucho, Int. J. Pharm., 2014, 469, 179-189.

12 K. Bica, C. Rijksen, M. Nieuwenhuyzen, R. D. Rogers, Phys. Chem. Chem. Phys., 2010, 12, 2011-2017.

13 I. M. Marrucho, L. C. Branco, L.P.N. Rebelo, Annu. Rev. Chem. Biomol. Eng., 2014, 5, 527-546.

14 R. Ferraz, V. Teixeira, D. Rodrigues, R. Fernandes, C. Prudêncio, J. P. Noronha, Z. Petrovski, L. C. Branco, RSC Adv., 2014, 4, 4301-4307.

15 R. Ferraz, J. Costa-Rodrigues, M. H. Fernandes, M. M. Santos, I. M. Marrucho, L. P. N. Rebelo, C. Prudêncio, J. P. Noronha, Z. Petrovski, L. C. Branco, ChemMedChem, 2015, 10, 1480-1483.

16 T. L. Greaves, C. J. Drummond, Chem. Rev., 2015, 115, 11379-11448.

17 R. Frade, A. A. Rosatella, C. S. Marques, L. C. Branco, P. S. Kulkarni, N. M. M. Mateus, C. A. M. Afonso, C. M. M. Duarte, Green Chem., 2009, 11, 1660-1665.

18 M. Mahato, S. Yadav, P. Kumar, A. K. Sharma, BioMed Res. Internat., 2014, Article ID 459736, 11 pages.

19 M. Mahato, G. Rana, P. Kumar, A Kumar Sharma, J. Pol. Science Part A: Polymer Chemistry, 2012, 50, 23442355.

20 S.-K. Mikkola, A. Robciuc, J. Lokajová, A. J. Holding, M. Lämmerhofer, I. Kilpeläinen, J. M. Holopainen, A. W. T. King, S. K. Wiedmer, Environ. Sci. Technol. 2015, 49, 1870-1878.

21 D. S. Patel, J. R. Avalani, D. K. Raval, J. Braz. Chem. Soc. 2012, 23, 1951-1954.

22 Z.-Z. Yang, L.-N. He, Y.-N. Zhao, B. Li, B. Yu, Energy Environ. Sci., 2011, 4, 3971-3975.

23 J. Nowicki, M. Muszyński, S. Gryglewicz, J. Chem. Technol. Biotechnol., 2014, 89, 48-55.

24 Chemical properties database, http://www.chemicalbook.com/ (checked at 20/04/2017).

25 Physprop database, http://esc.syrres.com/fatepointer /search.asp (accessed 20/04/2017)

26 C. Baraldi, A. Tinti, S. Ottani, M.C. Gamberini, J. Pharm. Biom. Anal., 2014, 100, 329-340.

27 A. O. Surov, A. V. Churakov, G. L. Perlovich, Cryst. Growth Des., 2016, 16, 6556-6567.

28 B. Šuštar, N. Bukovec, P. Bukovec, J. Therm. Anal., 1993, 40, 475-481.

29 E. Dudognon, N. T. Correia, F. Danède, M. Descamps, Pharm. Res., 2013, 30, 81-89.

30 J.-S. Song, Y.-T. Sohn, Arch. Pharm. Res., 2011, 34, 8790.

31 B. Z. Nezhad, Korean J. Chem. Eng., 2002, 19, 992-995.

32 J. L. Vazquez, M. Berlanga, S. Merino, O. Domenech, M. Viñas, M. T. Montero, J. Hernandez-Borrell, Photochem. Photobiol., 2001, 73, 14-19.

33 C-L. Zhan, Y. Wang, J. Chem. Eng. Data, 2008, 53, 12951297. 